\title{
USO DE AERONAVE REMOTAMENTE PILOTADA (ARP) NO ESTUDO DA GEOMORFOMETRIA DE SANGRADOUROS: ESTUDO DE GASO DO BALNEÁRIO GASSINO, RS
}

\author{
Use of remote pilot aircraft (RPA) in the study of the washouts \\ geomorphometry: case study at Cassino Balneary, RS
}

\author{
Julia Carballo Dominguez de Almeida ${ }^{1}$, Miguel da Guia Albuquerque ${ }^{2}$, \\ Deivid Cristian Leal Alves ${ }^{3}$, Jean Marcel de Almeida Espinoza² \\ ${ }^{1}$ Graduação em Geografia na Universidade Federal do Rio Grande. E-mail: cdalmeida.j@gmail.com \\ 2 Departamento de Geoprocessamento do Instituto Federal do Rio Grande. Rua Eng. Alfredo Huch, 475, Campus Rio \\ Grande, Rio Grande - RS. E-mail: migueldaguia@gmail.com; jean.espinoza@riogrande.ifrs.edu.br \\ ${ }^{3}$ Programa de Pós-Graduação em Geociência na Universidade Federal do Rio Grande do Sul. Av. Bento Gonçalves, \\ 9500, Campus do Vale, Porto Alegre - RS. E-mail: dclealalves@gmail.com
}

\begin{abstract}
RESUMO
Este trabalho teve como objetivo avaliar a aplicação das geotecnologias na construção de Modelos Digitais de Superfície (MDS) para dois sangradouros localizados na praia do Cassino, município do Rio Grande, RS. O emprego das geotecnologias, como a aeronave remotamente pilotada (ARP) e o receptor GNSS-RTK, resultou na construção de seis MDS, dois para cada dia de voo, dos canais com resolução espacial entre 5,05 cm e 5,26 cm. Ressaltamos que o uso das técnicas de geoprocessamento e a aplicação da ARP são de grande valor no aprimoramento de estudos sobre as zonas costeiras e os sangradouros do Balneário Cassino.
\end{abstract}

Palavras-chave: geotecnologias, geomorfologia costeira, sangradouros, drone.

\begin{abstract}
This work aims to evaluate the application of geotechnologies in the construction of Digital Surface Models (DSM) for two washouts located at Cassino Beach, Rio Grande, RS. The use of
\end{abstract}

Recebido em: 12/11/2019

Aprovado em: 26/06/2020

Publicado em: 30/01/2021 
geotechnologies such as remote pilot aircraft (RPA) and GNSS-RTK receiver resulted in the construction of six DSMs, two for each flight day, of channels with Ground Sample Distance (GSD) between $5.05 \mathrm{~cm}$ and $5.26 \mathrm{~cm}$. We emphasize that the use of RPA and application geoprocessing techniques are of great value in the improvement of studies on the coastal areas and washouts of the Cassino beach.

Keywords: geotechnologies, coastal geomorphology, washouts, drone.

\section{INTRODUÇÃO}

As zonas costeiras são espaços delimitados pelas porções terrestre e oceânica, onde a parte subaérea é afetada pela sua proximidade com a dinâmica costeira e a porção subaquosa pela proximidade com a dinâmica de escoamento e transporte sedimentar dos continentes (Serpa, 2008). No que diz respeito à geomorfologia fluvial, as zonas costeiras têm influência direta no funcionamento dos canais de drenagem das paisagens litorâneas, já que um dos fatores que definem as mudanças morfológicas desses canais é exatamente a ação de ondas e dos ventos que atingem a costa.

No contexto da barreira arenosa do Rio Grande do Sul, o termo "sangradouro" se refere aos canais que drenam o excedente hídrico da planície costeira em direção ao mar (Figura 1-A), deslocando água e sedimentos do continente para a zona de espraiamento (Figueiredo \& Calliari, 2005; Serpa 2008). Segundo Serpa et al. (2011), os sangradouros atuam no escoamento das zonas úmidas costeiras, originárias do acúmulo das águas pluviais em regiões adjacentes à praia, geralmente no reverso dos cordões de dunas (áreas de banhado). Os sangradouros cumprem assim a principal função de transportar as águas interiores para a jusante costeira ao romper o cordão de dunas frontais e desaguar no sistema praial.

No caso do Balneário Cassino, área de estudo deste trabalho, os sangradouros cumprem a importante função de realizar o escoamento das águas pluviais do interior da área urbana em direção à praia (Serpa, 2013), visto o pequeno gradiente de declividade. Porém, o aumento populacional, e o consequente crescimento urbano que amplia a área impermeabilizada, eleva a demanda dos canais de escoamento costeiros, sobrecarregando os sangradouros e aumentando a vulnerabilidade urbana a alagamentos. $O$ crescimento populacional do Balneário Cassino tem acarretado um aumento considerável no número de construções irregulares e inadequações na infraestrutura de escoamento das águas pluviais. A dificuldade na gestão das águas urbanas superficiais tem causado prejuízos à população local durante o período de chuvas fortes ou de longa duração (Figura 1-B).

A compreensão sobre os processos hidrológicos é fundamental na gestão dos recursos hídricos e dos canais de drenagem. Nesse sentido, o emprego de modelos geomorfométricos pode auxiliar na análise de sistemas de drenagem através da construção de Modelos Digitais de Elevação (MDE). Conforme Pike (2000), a Geomorfometria é a área do conhecimento oriunda dos estudos da Geografia, Geomorfologia, Geofísica e, entre outras áreas das chamadas Geociências, que combina os atributos terrestres com a Matemática, a Engenharia e a Ciência da Computação na composição numérica das formas do relevo e de paisagens contínuas. Nesse sentido, o uso de técnicas geoespaciais, como MDE, pode ajudar na compreensão da geomorfologia dos canais de drenagem através de produtos de 
alta resolução e precisão, o que é essencial para um melhor entendimento dos processos envolvidos no ambiente costeiro (Wood, 1996).

Diante do exposto, o estudo visa elaborar modelos geomorfométricos a partir de dados coletados por uma aeronave remotamente pilotada (ARP), de modo a caracterizar a geomorfometria e o comportamento morfológico dos canais de drenagem costeiros (sangradouros) através de Modelos Digitais de Superfície (MDS).

Figura 1 - A) Sangradouro do Balneário Cassino; B) Registro de alagamento nas ruas do Balneário Cassino
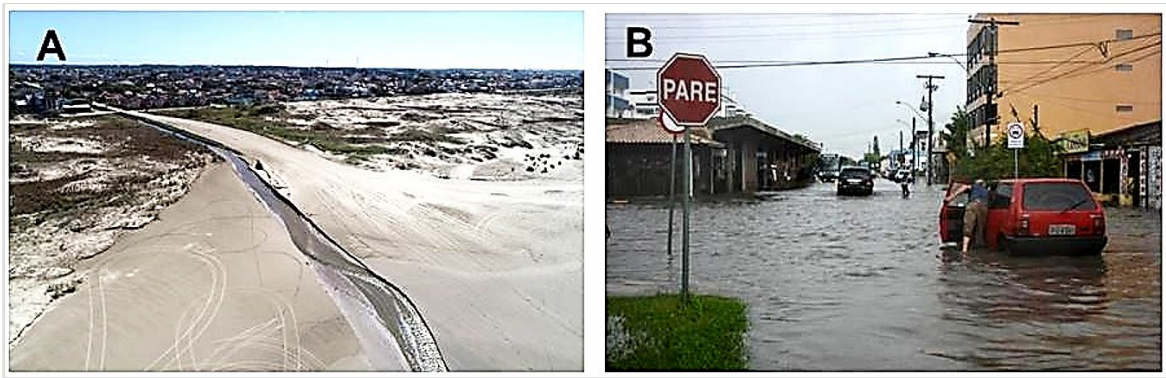

Fonte: Jornal Zero Hora (15/2/2013).

\section{MATERIAL E MÉTODOS}

\section{Área de estudo}

O Balneário Cassino localiza-se no município do Rio Grande, sul do estado do Rio Grande do Sul (Figura 2). A localidade é um dos maiores atrativos da região no período de veraneio onde, de acordo com a Prefeitura Municipal do Rio Grande, em média, o balneário chega a receber aproximadamente 150 mil turistas de todo o Rio Grande do Sul e países vizinhos, como Uruguai e Argentina. A praia do Cassino pode ser classificada como oceânica e dominada por ventos e ondas (Calliari \& Toldo Jr., 2016). A localidade apresenta alta umidade e um regime de chuvas bem distribuído ao longo do ano, com volumes máximos registrados principalmente no período de inverno. De acordo com Reboita, Krusch e Piccoli (2006), o clima na região é influenciado fortemente pelos sistemas atmosféricos de pequena escala temporal, com ação diária ou mesmo semanal, conforme a atuação de frentes vindas do quadrante sul, por exemplo. Já os fatores interanuais, como o fenômeno El Niño e La Niña, possuem forte influência no regime pluviométrico.

\section{Coleta e análise de dados}

A etapa de planejamento foi feita em laboratório, com a construção dos planos de voo para os dois canais (Figura 3). Nessa etapa foram tomadas as decisões e a determinação dos comandos a serem executados pela ARP durante o sobrevoo, como, por exemplo, a área do mapeamento, a sobreposição lateral e frontal (60\% e 70\%, respectivamente), a orientação das linhas de voo e a altura da aquisição das imagens (50 metros), que foram determinadas a partir das especificidades da área de estudo. Como a análise foi realizada sobre dois canais de drenagem distintos, foram montados dois planos de voo seguindo configurações semelhantes. Foi utilizado o valor 100 para a ISO, devido à alta luminosidade de ambientes das praias. O tempo de voo para todos os levantamentos não ultrapassou 15 minutos. 
Figura 2 - Mapa de localização da área de estudo

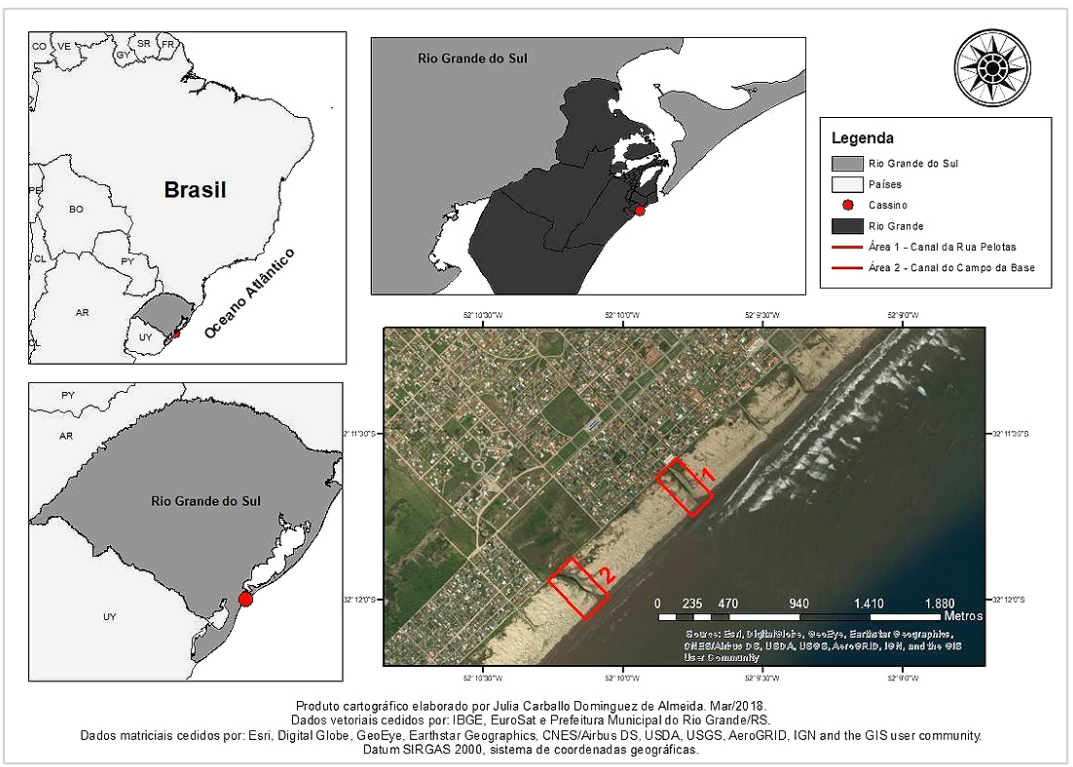

Figura 3 - Exemplo de plano de voo elaborado no aplicativo DroneDeploy®

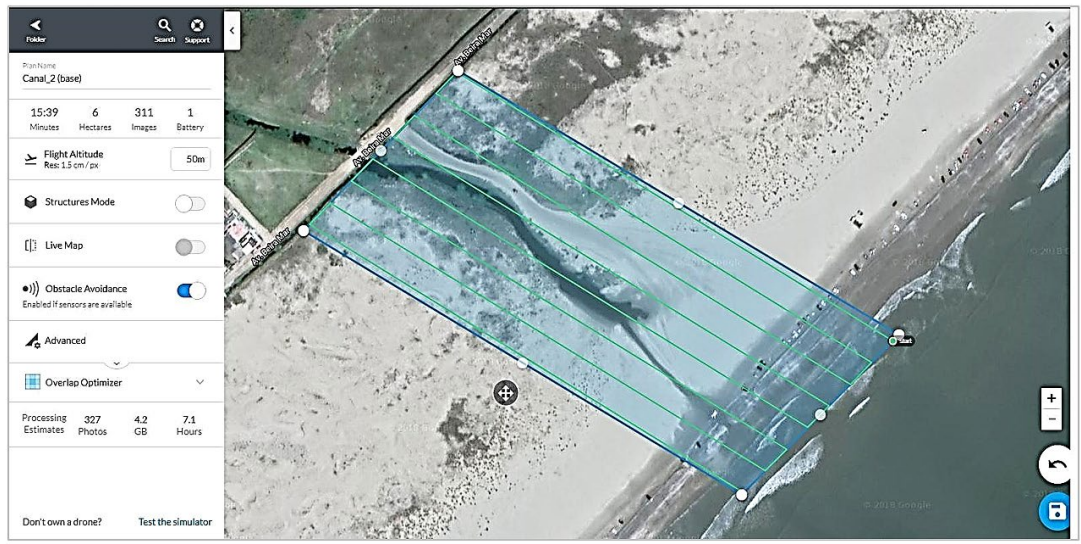

A praia do Cassino é conhecida por suas fortes rajadas de vento e essa informação foi de extrema relevância para a construção do plano, já que a influência dos ventos pode prejudicar tanto a qualidade das imagens obtidas quanto a estrutura física da aeronave. Por isso, antes de cada coleta de dados, foram verificadas as condições meteorológicas para o dia e hora da execução do voo, especialmente a velocidade dos ventos, inclusive com aferição através de anemômetro manual minutos antes da execução do voo.

Em campo foram instalados 12 corpos de prova (cilindros de concreto), seis nas margens de cada sangradouro, que serviram como pontos de controle no solo para posterior ajuste dos blocos durante o processamento das imagens e a geração dos modelos digitais de superfície (MDS). Cada corpo de prova foi ocupado por instrumentação geodésica, com a aquisição de coordenadas planialtimétricas (X, Y e Z) executadas pelo receptor GNSS-RTK Leica GS 15 no modo stop-and-go. Ainda foram coletados pontos extras ao longo da área do levantamento com o objetivo de avaliar a qualidade do MDS através de pontos de checagem. Os valores elipsoidais $(\mathrm{h})$ coletados pelo receptor GNSS foram convertidos para 
altitudes ortométricas $(\mathrm{H})$ com uso do programa MAPGEO 2015, de forma com que os dados ficassem ajustados a partir de uma referência mais próxima ao nível do mar. A partir dessa conversão, os dados do GNSS-RTK foram utilizados para ajustamento do bloco fotogramétrico.

As imagens dos voos foram tratadas no software Agisoft Photoscan ${ }^{\circledR}$, onde o primeiro estágio do processo é o alinhamento das fotografias para a obtenção da tie points. O software fotogramétrico então identifica pontos homólogos por meio das imagens sobrepostas, organizando virtualmente o mosaico de tal forma que uma versão tridimensional das feições obtidas na cena possa ser processada na forma de uma densa nuvem de pontos (dense cloud) e, em seguida, georreferenciada. A nuvem de pontos gerada foi submetida ao método de interpolação do Inverso do Quadrado da Distância (Inverse Distance Weighted - IDW). Na sequência, foram geradas ortoimagens, as quais são uma imagem de "cor real" sem distorções geométricas, corrigindo a influência do relevo, da presença de objetos (postes, prédios, vegetação), e os efeitos das diferentes visadas. Ao final dos processamentos fotogramétricos, a qualidade dos modelos foi avaliada empregando o software GEOPEC.

\section{RESULTADOS}

Para o dia 17 de março de 2018 (Figura 4), o canal 1 teve sua resolução espacial horizontal no valor igual a 5,15 cm/pixel e o canal 2 registrou resolução igual a 5,13 cm/pixel. A partir dos modelos, foi possível identificar pela tonalidade assimilada as feições das porções praias dos sangradouros e áreas adjacentes, onde os valores mínimos registrados foram $0,86 \mathrm{~m}$ para o canal 1 e $0,32 \mathrm{~m}$ para o canal 2; enquanto as regiões de maior elevação, no caso as dunas, apresentaram valores máximos de 9,04 $\mathrm{m}$ para o canal 1 e 6,44 $\mathrm{m}$ para o canal 2, respectivamente.

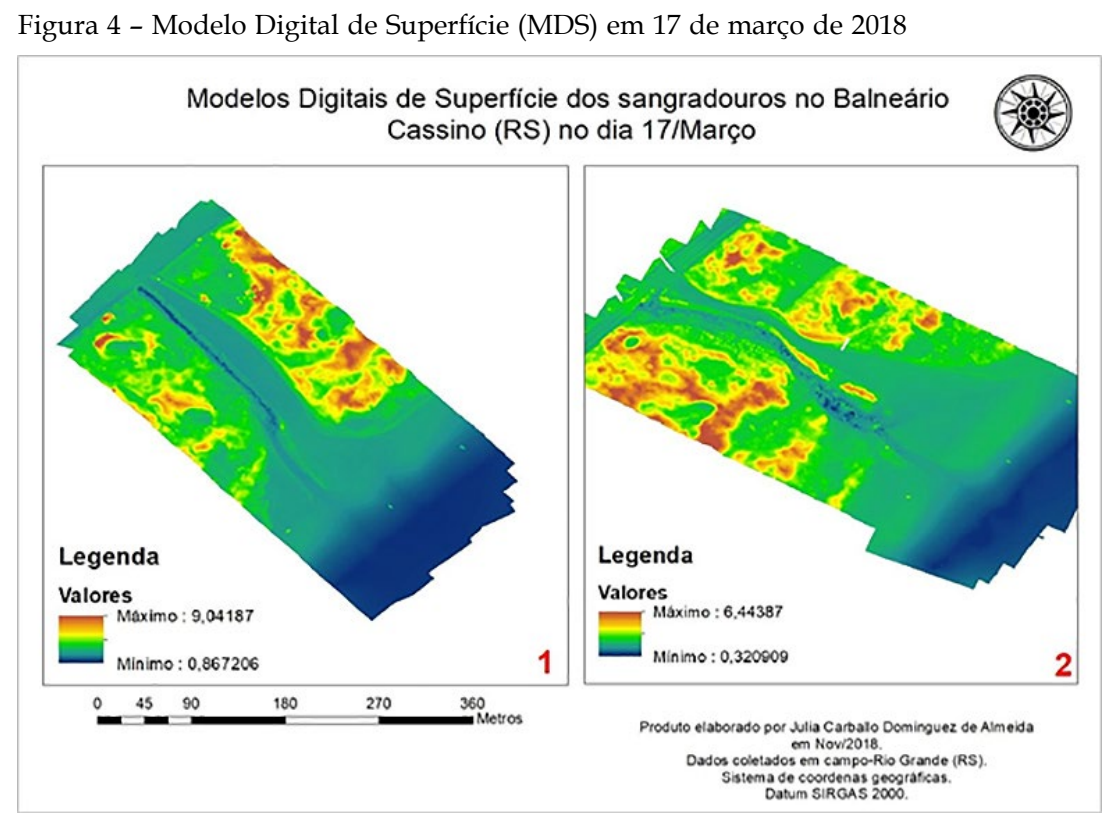

A construção do modelo do canal 1 no dia 19 de abril de 2018 apresentou uma resolução espacial igual a 5,51 cm/pixel e para o canal 2 o valor atribuído para a resolução espacial é de 5,26 cm/pixel. Os MDS do segundo dia de voo (Figura 5) apresentam poucas 
diferenças na escala da altitude em comparação com o primeiro dia de voo. O canal 1 apresentou uma cota máxima de 9,08 m e mínima de $0,40 \mathrm{~m}$. O canal 2 teve como valor máximo de altitude 6,35 m e mínimo igual a -0,70 m. O MDS do canal 2 apresenta uma pequena formação de dunas próximas ao sangradouro, com altitude considerável.

Figura 5 - Modelo Digital de Superfície (MDS) em 19 de abril de 2018

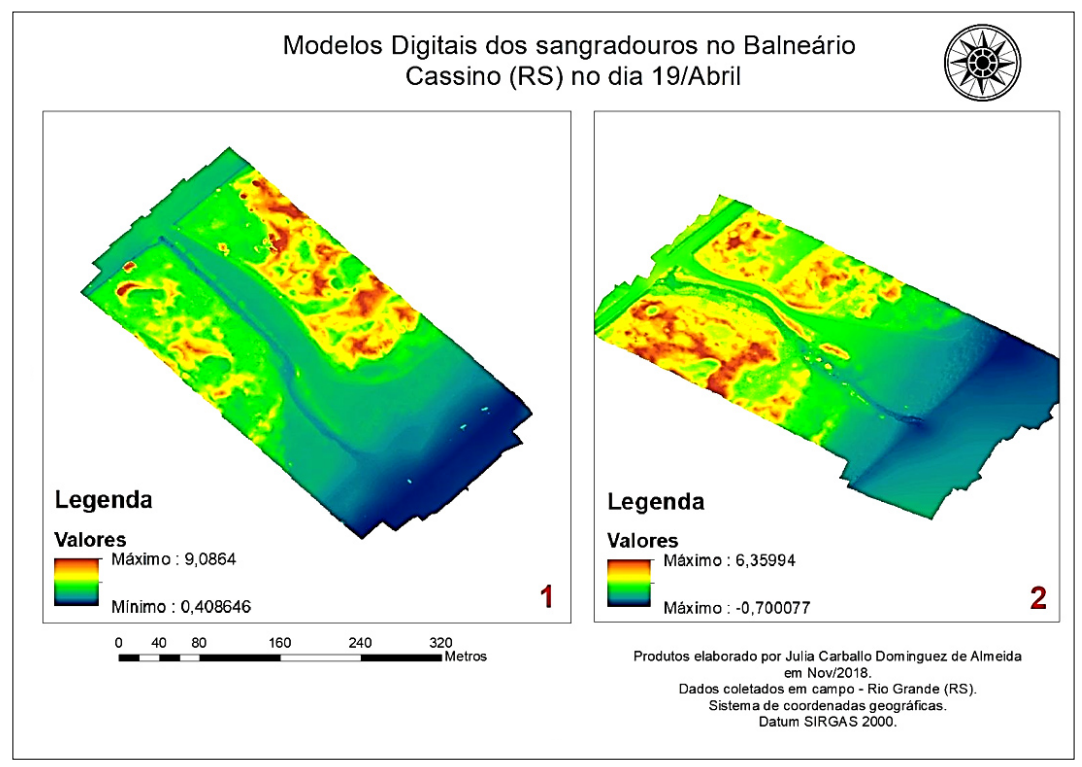

Já os MDS do dia 5 de setembro de 2018 compreenderam valores de resolução espacial de 5,2 cm/pixel para o canal 1 e 5,05 cm/pixel para o canal 2 (Figura 6). Em comparação com os demais modelos, é o que apresenta de forma mais nítida as feições da porção praial dos canais de drenagem, sendo que os valores de altitude mais baixos são justamente nos canais e na linha de costa, onde chegam a 0,36 m no canal 1 e 0,52 m no canal 2.

Figura 6 - Modelo Digital de Superfície (MDS) em 5 de setembro de 2018

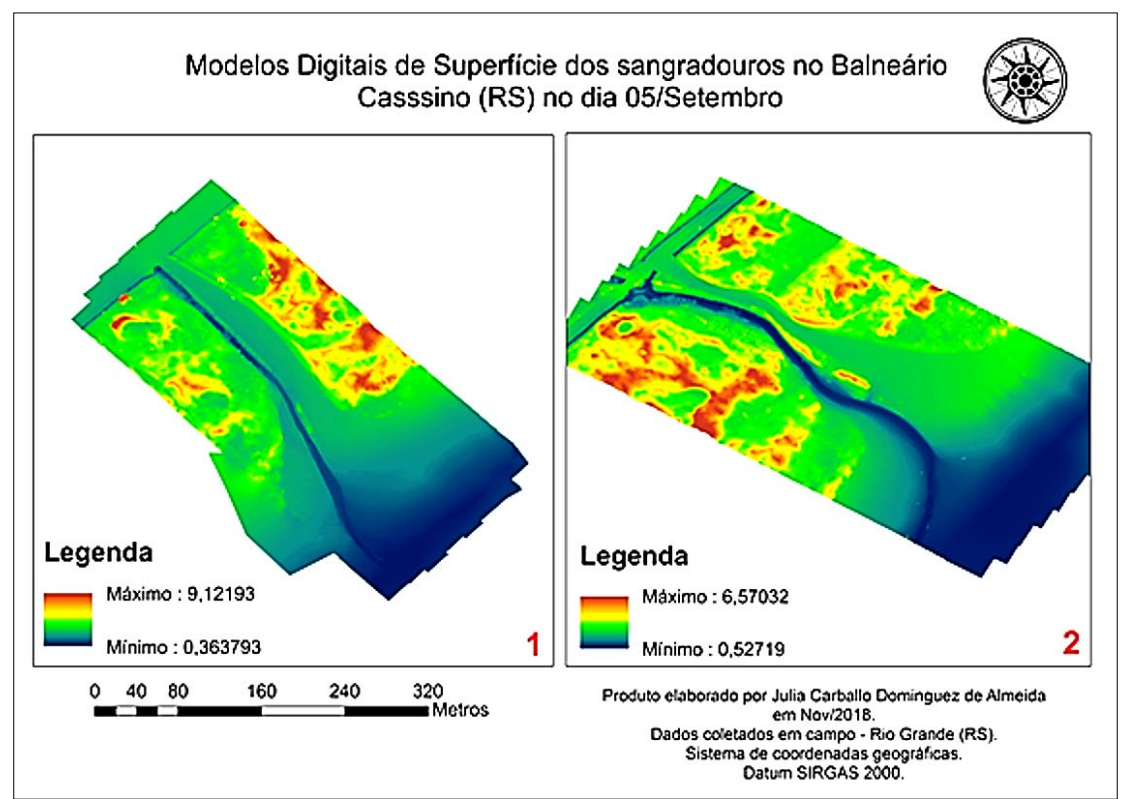


Esses valores e comportamento dos sangradouros podem ser associados à troca de estação, já que o levantamento ocorreu nas últimas semanas do inverno (período de maior precipitação e ocorrência de tempestades). As maiores altitudes continuam sendo registradas no cordão de dunas, com os valores máximos de altitude chegando a 9,21 m no canal 1 e 6,57 m no canal 2.

A partir desses modelos é possível identificar o comportamento do meandro do canal entre as datas estudadas. $\mathrm{O}$ segmento do canal que quase não atinge a costa indica que o fluxo de água não era intenso. Após o processamento dos dados, os erros em metros associados para estes canais no primeiro dia de coleta foram $0,015 \mathrm{~m}$ para o canal 1 e $0,022 \mathrm{~m}$ para o canal 2 (mapeamento realizado em 17/3/2018); de 0,019 m para o canal 1 e 0,048 m para o canal 2 no segundo dia de levantamentos (mapeamento realizado em 19/4/2018). E, finalmente, no último levantamento os erros associados foram de $0,025 \mathrm{~m}$ para o canal 1 e 0,020 m para o canal 2 (mapeamento realizado em 5/9/2018).

Com base na característica da área de estudo, da instrumentação e metodologia empregada, o erro vertical máximo estipulado para os mapeamentos foi de 0,05 $\mathrm{m}$. Isso demonstra que os resultados obtidos foram satisfatórios dentro do padrão estabelecido previamente. Por fim, uma análise inicial sobre os resultados já obtidos revela que as variações, que podem ter tanto origem antrópica (limpeza/desobstrução dos canais de drenagem com uso de máquinas) quanto meteo-oceanográfica (efeito das ondas de tempestades sobre o prisma praial, dos ventos sobre o transporte de areia e do volume de chuvas, que aumenta a vazão dos canais), alteram o comportamento não só da praia, mas também do campo de dunas adjacentes, além da própria geomorfologia dos canais que apresentam variações em cada um dos MDS obtidos.

\section{DISCUSSÃO}

Levantamentos com emprego de câmeras digitais de pequeno formato acopladas à ARP têm revolucionado a forma de aquisição, registro e processamento fotogramétrico (Turner; Harley \& Drummont, 2016). O emergente mercado de aeronaves remotamente pilotadas tem fornecido imagens de alta resolução a baixo custo econômico e operacional (Gonçalves \& Henriques, 2015). A instrumentação básica já apresenta significativa robustez, sendo que a adição de receptores GNSS-RTK em coletas de controle de solo tem ampliado as possibilidades, pois permite um incremento considerável na precisão dos produtos gerados através de algoritmos Structure-from-Motion (Colomina \& Molina, 2014; Clapuyt; Vanacker \& Oost, 2016).

Mesmo com certas limitações de uso, como as de origem meteorológica (vento, precipitação), tempo de voo (autonomia de bateria) e aquelas impostas pelos marcos regulatórios (altura de voo e áreas permitidas), o emprego de ARPs com câmeras digitais tem fornecido autonomia para o imageamento de alta resolução que outrora estava limitado a operações de alto custo e nem sempre com a escala temporal adequada (Gonçalves \& Henriques, 2015; Turner; Harley \& Drummont, 2016; Anac, 2017). Com um mínimo de planejamento, é possível realizar o recobrimento de pequenas áreas (Gonçalves \& Henriques, 2015), inclusive logo após eventos de interesse - no caso da paisagem costeira, eventos de alta energia, como inundações ou erosão, por exemplo.

Nesse sentido, os resultados alcançados ilustram as potencialidades do conjunto de métodos empregados. A praia do Cassino, assim como toda a costa do Rio Grande do Sul, 
apresenta uma significativa densidade de canais de drenagem com defluxo no prisma praial emerso e zona de surfe (Figueiredo \& Calliari, 2005). A baixa topografia, somada ao seccionamento do cordão de dunas frontais promovido pelos sangradouros, barreiras naturais de proteção da costa aos eventos de sobrelevação do nível do mar, tornam as costas arenosas do sul do Brasil um ambiente altamente vulnerável a episódios de inundação (Figueiredo \& Calliari, 2005; Serpa et al., 2011). O monitoramento fotogramétrico e a modelagem geomorfométrica dos sangradouros, identificando sua dinâmica morfológica (componentes sazonais, resiliência frente ao ataque de ondas; alteração dos meandros à beira-mar), podem oferecer ferramentas à gestão urbana ou mesmo auxiliar na intervenção na forma de manutenções apropriadas dos canais, bem como dos campos de dunas ao seu redor.

\section{CONCLUSÃO}

Com base nos modelos obtidos, foi possível considerar que a metodologia aplicada foi satisfatória para a elaboração do estudo. O padrão de precisão vertical dos modelos são provas de que a aplicação de geotecnologias tem grande potencial na construção de produtos geomorfométricos. As limitações impostas por outros métodos de aquisição de dados planialtimétricos tornam tais levantamentos dispendiosos em tempo e custos de campo, além de resultar em produtos com menor detalhamento. Portanto, futuramente, também seria de extrema relevância que fossem realizados outros aerolevantamentos com uma ARP de outra marca e porte, possibilitando a comparação dos resultados e da avaliação da qualidade dos produtos gerados por diferentes tipos de veículos aéreos.

Outra questão importante no emprego de ARPs se refere à exatidão dos dados. Os pontos de controle de solo aumentam a precisão dos MDS, mas devem ser acompanhados de pontos extras para a checagem através de testes de acurácia. Por fim, é possível concluir que este estudo torna-se uma ferramenta para a Gestão Costeira por garantir ao poder público, a partir da análise da geomorfometria dos canais de drenagem, a possibilidade de avaliar problemas relacionados a eventos extremos, como as inundações e os alagamentos, no Balneário Cassino, por meio do manejo adequado dos sangradouros e do planejamento da ação pública efetiva.

Agradecimentos - Os autores agradecem ao Departamento de Controle do Espaço Aéreo (Decea/Sarpas) pelo acesso ao espaço aéreo nos dias de levantamento. Os autores também agradecem ao prof. Afonso P. Santos, da Universidade Federal de Viçosa (UFV), pela disponibilização do software para avaliação da acurácia posicional em dados cartográficos GEOPEC (v. 3.5), e ao Instituto Federal do Rio Grande do Sul (IFRS) pela concessão da bolsa e apoio financeiro ao projeto.

\section{REFERÊNCIAS BIBLIOGRÁFICAS}

Anac. Regras sobre uso de drones. Disponível em: http://www.anac.gov.br/assuntos/ paginas-tematicas/drones>. Acesso em: 14 maio 2017.

Calliari, L.J. \& Toldo Jr., E.E. Ocean beaches of Rio Grande do Sul, p. 507-542, in Short, A.D. \& Klein, A.H.F. (eds.), Brazilian beach systems. Coastal Research Library, Springer, 611 p., Dordrecht, 2016. 
Clapuyt, F.; Vanacker, V. \& Oost, K.V. Reproducibility of UAV-based earth topography reconstructions based on Structure-from-Motion algorithms. Geomorphology, v. 260, p. 4-15, 2016. Doi.org/10.1016/j.geomorph.2015.05.011.

Colomina, I. \& Molina, P. Unmanned aerial systems for photogrammetry and remote sensing: a review. ISPRS Journal of Photogrammetry and Remote Sensing, v. 92, p. 79-97, 2014. Doi.org/10.1016/j.isprsjprs.2014.02.013.

Figueiredo, S.A. \& Calliari, L.J. Sangradouros: distribuição espacial, variação sazonal, padrões morfológicos e implicações no gerenciamento costeiro. Gravel, n. 3, p. 47-57, 2005.

Gonçalves, J.A. \& Henriques, R. UAV photogrammetry for topographic monitoring of coastal areas. ISPRS Journal of Photogrammetry and Remote Sensing, v. 104, p. 101-111, 2015. Doi.org/10.1016/j.isprsjprs.2015.02.009.

Pike, R.J. Geomorphometry - diversity in quantitative surface analysis. Los Angeles: US Geological Survey, 2000.

Reboita, M.S.; Krusche, N. \& Piccoli, H.C. Climate variability in Rio Grande, RS, Brazil: a quantitative analysis of contributions due to atmospheric systems. Rev. Bras. de Meteor., v. 21, n. 2, p. 256-270, 2006.

Serpa, C.G. Estudo da influência dos fatores climáticos e hidrológicos no ciclo morfodinâmico praial de um sangradouro intermitente, praia do Cassino, Brasil. Dissertação de mestrado, Programa de Pós-Graduação em Engenharia Oceânica, Universidade Federal do Rio Grande, 97 p., Rio Grande, 2008.

Serpa, C.G.; Romeu, M.A.R.; Fontoura, J.A.S.; Calliari, L.J.; Melo, E. \& Albuquerque, M.G. Study of the responsible factors for the closure of an intermittent washout during a storm surge, Rio Grande do Sul, Brazil. Journal of Coastal Research, v. 64, n. SI, p. 2068-2073, 2011.

Serpa, C.G. Morfodinâmica praial relacionada à presença de corpos de água intermitentes em duas praias da costa do Rio Grande do Sul, Brasil. Tese de doutorado, Programa de Pós-Graduação em Oceanografia Física, Química e Geológica, Universidade Federal do Rio Grande, Instituto Oceanográfico, 2013.

Turner, I.L.; Harley, M.D. \& Drummond, C.D. UAVs for coastal surveying. Coastal Engineering (Short communication), v. 114, p. 19-24, 2016.

Wood, J. The geomorphological characterization of digital elevation models. Tese de doutorado, Departamento de Geografia, Universidade de Leicester, 466 p., Leicester, 1996. 